\title{
O clima social de uma escola de ensino médio na percepção dos professores antes e durante a pandemia de Covid-19
}

\author{
The social climate of a high school in the perception of teachers before and during the \\ Covid-19 pandemic
}

\section{El clima social de una escuela secundaria en la percepción de los docentes antes y durante la pandemia de Covid-19}

\author{
Sáhira Michele da Silva Celestino ${ }^{1}$ \\ Rita de Cássia de Souza ${ }^{2}$
}

\section{Resumo}

O clima social escolar consiste em como as pessoas se sentem dentro da escola, estando relacionado às relações entre os professores, a gestão, os alunos, a família/comunidade, as atividades de ensino-aprendizagem e outros fatores internos e externos à escola e interfere no processo de ensino-aprendizagem e na qualidade de vida das pessoas envolvidas no ambiente escolar. Este artigo é parte de uma pesquisa visando compreender o clima social escolar no Ensino Médio de uma escola do Ensino Médio numa pequena cidade a Zona da Mata Mineira antes e durante a pandemia do Covid-19. A perspectiva teórica para o estudo foi o Construcionismo Social. Devido à pandemia e à inexistência de aulas presenciais, foi elaborado um questionário sobre temas relacionados ao clima social escolar antes e durante a pandemia. Dos 20 docentes do ensino médio da escola, sete devolveram o questionário. De maneira geral, os docentes relataram uma boa relação interpessoal com a gestão, os funcionários, os estudantes e a comunidade. Apesar do distanciamento social interferir no clima social da escola, consideramos que seria uma oportunidade para investigar se a pandemia teria afetado esse clima e de que forma. Os docentes enfatizaram que sentiam muita falta da convivência social e dos estudantes na escola.

Palavras-chave: Clima Social Escolar; Ensino Médio; Pandemia; Docentes; Construcionismo Social.

\begin{abstract}
The school social climate consists of how people feel inside the school and is related to the relationships among teachers, management, students, family/community, teaching-learning activities, and internal and external factors to the school. It interferes both in the teaching

\footnotetext{
${ }^{1}$ Doutoranda em Geografia pela Universidade Estadual Paulista; Mestra em Educação e licenciada em Geografia pela Universidade Federal de Viçosa. E-mail: sahira.celestino@ufv.br ORCID: https://orcid.org/0000-0001$\underline{6343-6889}$

${ }^{2}$ Doutora em Educação pela Universidade de São Paulo; Mestra em Educação e graduada em Psicologia pela Universidade Federal de Minas Gerais. Professora do Departamento de Educação da Universidade Federal de Viçosa. E-mail: ritasouza@ ufv.br ORCID: https://orcid.org/0000-0001-9823-6174
}

Revista Devir Educação, Lavras-MG. Edição Especial, p.71-89, Set./2021. 
process and also in the learning and the quality of life of people involved in the school environment. This article is part of a research that aimed to understand the school social climate in a high school in a small town in Zona da Mata Mineira before and during the Covid-19 pandemic. The theoretical perspective of the study was Social Constructionism. Due to the pandemic and the lack of face-to-face classes, a questionnaire was designed on topics related to the school's social climate before and during the pandemic. Out of the 20 high school teachers at the school, seven returned the questionnaire. In general, teachers reported a good interpersonal relationship with the administration, employees, students, and the community. Although social distancing affects the school's social climate. We believe it would be an opportunity to investigate whether the pandemic would have affected that climate and how. Teachers emphasized that they really miss social life and students at school.

Keywords: School Social Climate; High school; Pandemic; Teachers; Social Constructionism.

\section{Resumen}

El clima social escolar consiste en cómo se sienten las personas dentro de la escuela, estando relacionado con las relaciones entre profesores, dirección, alumnos, familia / comunidad, actividades de enseñanza-aprendizaje y otros factores internos y externos a la escuela e interfiere en el proceso de enseñanza-aprendizaje. y en la calidad de vida de las personas involucradas en el entorno escolar. Este artículo es parte de una investigación dirigida a comprender el clima social escolar en la escuela secundaria en un pequeño pueblo de la Zona da Mata Mineira antes y durante la pandemia de Covid-19. La perspectiva teórica del estudio fue el Construccionismo Social. Debido a la pandemia y la falta de clases presenciales, se diseñó un cuestionario sobre temas relacionados con el clima social escolar antes y durante la pandemia. De los 20 profesores de secundaria de la escuela, siete devolvieron el cuestionario. En general, los profesores reportaron una buena relación interpersonal con la gerencia, los empleados, los estudiantes y la comunidad. Aunque el distanciamiento social afecta el clima social de la escuela, creemos que sería una oportunidad para investigar si la pandemia habría afectado este clima y cómo. Los profesores enfatizaron que realmente extrañaban la interacción social y los estudiantes de la escuela.

Palabras clave: Clima social escolar; Escuela secundaria; Pandemia; Profesores; Construccionismo social.

\section{Introdução}

Cada vez mais, as pessoas passam muitos anos de suas vidas dentro de uma instituição de ensino e é muito provável que a maior parte do convívio social dos estudantes fora da família ocorra na escola. São muitas pessoas diferentes, de valores, costumes, hábitos e objetivos distintos reunidas por várias horas, dias e anos numa mesma instituição e algumas vivendo suas primeiras experiências de vida naquele local. Acreditamos que estas vivências impactam não somente seus aprendizados sobre os conteúdos propriamente escolares, mas são 
fundamentais para a constituição da autoimagem, da autoestima, para a construção de valores e o aprendizado sobre o convívio com os outros e todos os desafios que isso implica. No ensino remoto, as relações permanecem e também são essenciais para as nossas construções. Mesmo à distância, as relações existem e constroem os espaços virtuais, assim como constroem o clima escolar. Sendo assim, apesar das mudanças provocadas pelo distanciamento social, sem a convivência cotidiana escolar, as relações continuavam existindo, portanto, seria uma oportunidade de perceber o quanto os docentes percebiam o clima social da escola ao estarem exercendo as suas atividades, na ausência de relações cotidianas tão intensas.

Neste contexto, foi feita uma pesquisa sobre o clima social escolar no Ensino Médio de uma escola numa pequena cidade da Zona da Mata Mineira, na perspectiva do Construcionismo Social e destacamos aqui a percepção dos professores sobre a relação com os discentes, funcionários e gestores da escola antes e durante o período de distanciamento social e ensino remoto. Para isso, vamos apresentar o Construcionismo Social e em que medida consideramos que ele pode ser útil para o nosso estudo, discutir o conceito de clima social escolar e suas implicações para os envolvidos; apresentar o clima social escolar na escola pesquisada na visão dos educadores antes e durante a pandemia.

\section{Caminho metodológico percorrido}

Na escola pesquisada, as aulas foram suspensas no mês de março de 2020, por tempo indeterminado e a Secretaria de Estado de Educação de Minas Gerais (SEE/MG) elaborou o Regime de Estudo não presencial. Para tanto, foi ofertado aos estudantes um Plano de Estudos Tutorado (PET), organizado de acordo com o Currículo Referência de Minas Gerais ${ }^{3}$ e com o Plano de Curso da unidade de ensino ${ }^{4}$ com atividades não presenciais que os alunos faziam

\footnotetext{
${ }^{3}$ O Currículo Referência de Minas Gerais é um documento elaborado pela Secretaria de Estado de Educação de Minas Gerais (SEE/MG) e a União Nacional dos Dirigentes Municipais de Educação, seccional Minas Gerais (Undime-MG) e tem por objetivo oportunizar que todos os estudantes, independente da rede em que eles estejam matriculados, tenham garantia e acesso à aprendizagem que está descrita no currículo formatado a partir da Base Nacional Comum Curricular (BNCC).

4 “O plano de unidade, ou unidade de ensino, é uma previsão mais específica e analítica do trabalho a ser desenvolvido durante um determinado período/tempo. Este plano procura reunir, num todo organizado, mais
} 
em casa, via internet (e-mail) ou impressas (para os estudantes que não tinham internet em casa). Os professores poderiam receber os materiais via e-mail, WhatsApp ou de maneira impressa. Além disso, estudantes e docentes poderiam acessar uma plataforma digital para acessarem os Planos de Estudos Tutorados e as aulas gravadas sobre os conteúdos que foram transmitidos pela Rede Minas ${ }^{5}$.

Diante deste novo contexto, a pesquisa foi realizada através de um questionário, elaborado pela pesquisadora e organizado em três seções: a primeira correspondia à identificação dos professores, a segunda dizia respeito às relações construídas na escola e a última se referia ao contexto pandêmico (como se sentiam em trabalhar neste período). $\mathrm{O}$ questionário entregue aos professores era composto por 40 questões: 4 abertas e 36 fechadas com opções dentro da escala Likert. A análise dos resultados foi realizada a partir dos cinco ângulos inter-relacionados propostos por Janosz, Georges e Parent (1998): o clima relacional, o clima educacional, o clima de segurança, o clima de justiça e o clima de pertença.

Os 20 professores do ensino médio da escola receberam o questionário através do Google Forms, bem como o Termo de Consentimento Livre e Esclarecido e a carta de apresentação da pesquisa no dia 30/09/2020 e tiveram um mês para devolvê-lo. Sete professores participaram da pesquisa, 4 mulheres e 3 homens ${ }^{6}$.

\section{A perspectiva Construcionista Social}

Segundo Emerson Rasera e Marisa Japur (2005), o construcionismo social surgiu alimentado por várias críticas aos modos tradicionais de fazer pesquisa que podem ser organizadas em três grandes grupos: a crítica social, a ideológica e a retórico-literária. A primeira emergiu diante da crítica da gênese social do pensamento científico por alguns autores como Marx, Weber, Scheler e Karl Mannheim; a crítica ideológica é baseada na teoria crítica da Escola de Frankfurt-Horkheimer, a partir de autores como Adorno, Marcuse e

específico temas ou conteúdos listados, que se inter-relacionem e se complementem, compondo um conjunto mais facilmente compreensível, devido a sua significação" (PORTAL EDUCAÇÃO, 2013).

${ }^{5}$ Durante a pandemia, os alunos poderiam assistir a aulas na TV, de segunda à sexta-feira na Rede Minas.

Disponível em: http://redeminas.tv/ . Acesso em: 05 mai. 2021.

${ }^{6} \mathrm{O}$ número do protocolo de aprovação da pesquisa pelo Comitê de Ética é CAAE: 29754120.8.0000.5153. 
Benjamim que questionam a ideia de neutralidade na ciência. Por fim, a crítica retóricoliterária defende que a própria escrita científica utiliza descrições e explicações que não são neutras e não apenas descrevem a realidade, mas a constituem, conforme a linguagem utilizada.

O movimento construcionista social surgiu, nos anos 1970, inspirado por estas críticas e reunindo autores, que, apesar de sua heterogeneidade, construíram e disseminaram estas ideias, como Kenneth Gergen, Mary Gergen, Vivien Burr, Dian Marie Hosking, Lupicínio Íñiguez-Rueda e, no Brasil, Mary Jane Paris Spink, Emerson Rasera, Maria Conceição Nogueira, Carla Guanaes-Lorenzi e Marisa Japur, entre outros.

A perspectiva construcionista social parte do pressuposto de que o acesso dos seres humanos ao mundo e ao significado das coisas não é direto, mas sempre mediado pela linguagem e pelos outros. Trazendo esta concepção para o nosso tema de estudos, consideramos, portanto que o clima social escolar, assim como outras concepções e objetos, é construído por meio das relações sociais. O construcionismo social enxerga o mundo como uma construção social, isto é, o conhecimento é sustentado por processos sociais, "isso requer dizer que o conhecimento do mundo e as formas comuns de o compreender são produções coletivas e compartilhadas na coletividade, ou seja, as versões do conhecimento constroem-se através das interações diárias entre as pessoas" (CARDOSO; BEIRAS, 2017, p. 6). Por isso, acreditamos que são as relações entre as pessoas que constroem e caracterizam o clima social da escola.

Para Eliane Cadoná e Helena Scarparo (2015, p. 2722), pensar sob a perspectiva construcionista significa "compreender que a construção da realidade se dá em meio aos coletivos e, portanto, não é possível falar de individualidades descoladas da cultura e dos modos que as pessoas elegem para vivenciar uma dada realidade”. Segundo as autoras, o construcionismo analisa a produção de sentidos no cotidiano de maneira coletiva e compreende cada contexto em sua particularidade.

Com base no construcionismo social, compreendemos que somos seres relacionais, coletivos e não individuais e as relações "entre" as pessoas são o que constrói o ambiente escolar. Desta forma, Rita Souza (2020) nos ajuda a entender as relações:

Como produtos e produtores de uma construção coletiva, cada relação em que participamos, cada contato que temos nos altera e altera os demais, influenciando a nossa constituição psíquica e o ambiente à nossa volta. As

Revista Devir Educação, Lavras-MG. Edição Especial, p.71-89, Set./2021. 


\section{OO DEVIR EDUCAÇÃO \\ ISSN: 2526-849X}

novas tecnologias, especialmente as TIC's, tecnologias de informação e comunicação, provocaram uma revolução na nossa forma de relacionar com o mundo e com as pessoas, pois elas aproximam diferentes e variados contextos culturais e nos transformam profundamente, já que somos, precisamente, este conjunto de relações (SOUZA, 2020, p. 3).

O contexto pandêmico exigiu uma várias alterações no comportamento humano, como um maior distanciamento social, objetivando conter a disseminação do vírus, fazendo com que as tecnologias de informação e comunicação se tornassem ainda mais importantes para conectar as pessoas, "encurtando" o afastamento e o distanciamento entre elas. Essa conexão virtual reduz o impacto psicológico do isolamento social e proporciona uma nova maneira para as pessoas se relacionarem. Além disso, aproxima diferentes contextos sociais e culturais que são fundamentais na construção das relações.

Analisar o clima social na perspectiva construcionista é entender que a construção deste está no "entre" das relações sociais. O construcionismo social considera que o processo de interação social é essencial para a formação do eu e do outro. Assim, "O processo de conhecer outras pessoas requer aprendizado constante: como estar com elas, responder a elas, agir em relação a elas" (SAMPSON, 2008, p. 104). A visão relacional do construcionismo social pode ser muito útil à ideia do clima social escolar que é construído por meio das relações sociais.

\section{Definições de clima social escolar e suas implicações para os envolvidos}

Segundo Kenneth Gergen (2009), a orientação construcionista social busca explicar os processos (que ocorrem de forma coletiva e não individualista) pelos quais as pessoas descrevem, explicam, ou, de alguma forma, dão conta do mundo em que vivem, incluindo-se a si mesmas. Então, para nós, explicar o processo de construção do clima social é compreender como são as relações das pessoas dentro do ambiente escolar porque são elas que constroem esse clima. Além disso, mesmo estando distantes, por causa do ensino remoto, as relações na escola continuam a existir, mesmo que sem a intensidade da interação cotidiana, mas elas permanecem construindo o clima social daquela instituição escolar. De acordo com Gergen,

Revista Devir Educação, Lavras-MG. Edição Especial, p.71-89, Set./2021. 
Entendemos o mundo são artefatos sociais, produtos historicamente situados de intercâmbios entre as pessoas. Do ponto de vista construcionista, o processo de compreensão não é automaticamente conduzido pelas forças da natureza, mas é o resultado de um empreendimento ativo, cooperativo, de pessoas em relação. Sob este enfoque, a investigação é atraída às bases históricas e culturais das várias formas de construção do mundo (GERGEN, 2009, p. 303).

Ao revisar a literatura sobre clima social escolar, percebemos que as definições são similares: Alda Maria Ceia (2011) o define como um conjunto de efeitos subjetivos, ou seja, como as pessoas se sentem na escola; Cristóbal Guerra Vio, Judith Vargas Castro, Lorena Castro Arancibia, Hugo Plaza Villarroel e Paulina Barrera Montes (2012) consideram que o clima social escolar corresponde à qualidade das relações existentes na escola; e Rodrigo Cornejo e Jesús Redondo (2001) afirmam que o clima social escolar consiste na percepção que os sujeitos têm sobre as relações interpessoais no contexto escolar.

Para Janosz, Georges e Parent (1998), o clima escolar refere-se principalmente aos valores e atitudes dominantes na comunidade, levando em consideração as relações sociais, o valor atribuído aos indivíduos, à missão educativa da escola e à instituição como meio de vida. Estes autores abordam a construção do clima escolar a partir de cinco ângulos interrelacionados:

1. Clima relacional: refere-se especificamente ao clima que reina nas relações entre os indivíduos, sendo também denominado clima social. É a dimensão socioemocional das relações humanas.

2. Clima educativo: reflete o valor dado à educação. Um clima educacional de qualidade implica que a escola seja percebida como um verdadeiro lugar de educação, ou seja, dedicado ao sucesso dos alunos e também ao seu bem-estar, fornecendo uma boa educação, transmitindo o valor da escolaridade e dando sentido à aprendizagem.

3. Clima de segurança: remete à ordem e à tranquilidade do meio ambiente, condições essenciais para a concentração que permeia as tarefas escolares.

4. Clima de justiça: marcado por uma justa valorização, reconhecimento e respeito pelos direitos e méritos de cada um. O clima de justiça ocorre através do reconhecimento da legitimidade e justiça das regras, sua aplicação judiciosa ou avaliações escolares justas; o sentimento de que o mérito ou a punição refere-se ao comportamento, em vez da própria pessoa.

Revista Devir Educação, Lavras-MG. Edição Especial, p.71-89, Set./2021. 
5. Clima de pertencimento: Esta dimensão transcende as outras facetas do clima escolar, na medida em que se desenvolve a partir dos outros climas que foram citados anteriormente. Quanto mais os indivíduos têm a impressão de que seu meio é significativo, que promove o contato humano, que garante sua proteção e o reconhecimento de seu direito e de seu esforço da mesma forma que sanciona de forma justa e equitativa suas transgressões à norma, mais fácil é desenvolver um sentimento de pertença. Esse sentimento fortalece o respeito à instituição e às pessoas que nela vivem e facilita a adesão aos padrões ali estabelecidos (JANOSZ; GEORGES; PARENT, 1998).

O clima social escolar consiste em como as pessoas se sentem dentro da escola. Está diretamente ligado às relações entre os professores, a gestão, os alunos, a família/comunidade, bem como às atividades de ensino-aprendizagem. A construção do clima social se dá dentro de sala de aula, no recreio, na relação com o horário das aulas, os conteúdos escolares, as regras pedagógicas, avaliações, etc. e interfere no processo de ensino-aprendizagem e na qualidade de vida das pessoas envolvidas no ambiente escolar.

Ana María Aron, Neva Milicic e Iván Armijo (2012) dizem que o bom clima social escolar faz com que as pessoas se sintam valiosas e importantes naquele ambiente, se sintam reconhecidas, pertencentes à instituição, respeitadas em sua dignidade, individualidade e diferenças. Portanto, um bom clima social na escola favorece o crescimento pessoal e coletivo, estimula a criatividade e o envolvimento geral na resolução de problemas. Por outra parte, os autores dizem que, quando o clima social escolar se apresenta ruim, a tendência entre as pessoas é focar nos erros.

O afeto é construído historicamente e compartilhado culturalmente, sofrendo mudanças à medida que os indivíduos se desenvolvem e interagem uns com os outros (ARANTES, 2003). Para Beaudoin e Taylor (2006, p. 119), "Não há nada pior do que se sentir sozinho na multidão". O bom clima social escolar promove a aprendizagem e o desenvolvimento dos discentes, melhorando o relacionamento entre eles e os professores, favorecendo que a escola seja considerada um local de acolhimento e crescimento de oportunidades, gerando motivação e estimulando a construção de vínculos (PÉREZ, 1999). Por outro lado, um clima social ruim promove a ausência de companheirismo entre os colegas, exclusão social, afetando a comunicação, o bem-estar social, o desenvolvimento de atividades e o aprendizado (OESSELMAN, 2009). 


\section{OO DEVIR EDUCAÇÃO \\ ISSN: 2526-849X}

Relações sociais pautadas na intolerância às diferenças podem estimular várias formas de violência, diretas e indiretas, aumentando também a evasão e o abandono escolar gerando um clima social desagradável, prejudicando a qualidade de vida daqueles que ficam na instituição. O clima social ruim está relacionado à violência (física, verbal, social ou a combinação delas), à ausência de companheirismo entre os colegas, à exclusão social, entre outros fatores. As relações negativas afetam a comunicação, o bem-estar social, o desenvolvimento de atividades e aprendizado (OESSELMAN, 2009). Numa instituição com um bom clima social, os professores se esforçam para lidar, da maneira mais justa e inclusiva possível, com as dificuldades e problemas cotidianos. Sentir-se bem na instituição escolar é um bom preditor para bons resultados acadêmicos, além de minimizar os desafios que envolvem a aprendizagem e as relações interpessoais.

É preciso destacar que, como o clima social é uma medida interacional, é claro que o distanciamento social o afeta, diminuindo talvez a sua força, considerando-se que as pessoas não estão tendo tanto contato em várias horas por dia como nas atividades presenciais escolares. Ainda assim, a relação com a escola existe, já que todos continuam membros daquela instituição. A saída encontrada foi, portanto, fazer uma pesquisa com o mínimo contato interpessoal possível, perguntando como os educadores se sentiam na escola antes e durante o período da pandemia e se desejavam ou não o retorno às atividades presenciais.

\section{Resultados e discussão: O clima social escolar na escola pesquisada na visão dos educadores}

Sete professores participaram da pesquisa, 4 mulheres e 3 homens: 2 homens e 2 mulheres se declararam brancos, 1 professor e 1 professora pardos e 1 professora preferiu não identificar a sua cor. Mostramos, a seguir, a formação destes professores, o ano em que terminaram a graduação e as disciplinas que ministravam.

\begin{tabular}{cccc}
\multicolumn{4}{c}{ Tabela 1.0 - Formação dos professores } \\
\hline $\begin{array}{c}\text { Ano de } \\
\text { Sonclusão Feminino }\end{array}$ & $\begin{array}{c}\text { Graduação } \\
\text { Lecionava } \\
\text { para: }\end{array}$ & $\begin{array}{c}\text { Ministrava a } \\
\text { disciplina: }\end{array}$ \\
\hline 2000 & $\begin{array}{c}\text { Pedagogia e } \\
\text { Educação }\end{array}$ & $1^{\circ}$ ano & $\begin{array}{c}\text { Arte e Projeto de } \\
\text { Vida }\end{array}$
\end{tabular}

Revista Devir Educação, Lavras-MG. Edição Especial, p.71-89, Set./2021. 


\begin{tabular}{cccc}
\hline \multicolumn{4}{c}{ Artística } \\
2008 & Filosofia & $3^{\circ}$ ano & Filosofia \\
2009 & Pedagogia & - & Supervisão \\
1998 & Zootecnia & $1^{\circ}$ ano & Biologia \\
\hline \multicolumn{4}{c}{ Sexo Masculino } \\
\hline 2002 & Matemática & - & - \\
2011 & História & - & - \\
2019 & Geografia & $1^{\circ}$ ano & Geografia \\
\hline \multicolumn{4}{c}{ Fonte: Das autoras $(2020)}$. \\
\hline
\end{tabular}

Dois docentes participantes da pesquisa, naquele momento específico, não estavam ministrando aulas, pois trabalhavam na Secretaria Geral e Gestão escolar. Os demais educadores ministravam aulas para o $1^{\circ}$ ano e na Educação para Jovens e Adultos - EJA, 1 professora e 1 professor davam aulas para o $3^{\circ}$ ano. Nenhum professor do $2^{\circ}$ ano respondeu $o$ formulário.

Assim como os estudantes, os docentes passam grande parte do dia na instituição e as relações construídas por eles dentro da escola são fundamentais para a construção do clima social da instituição. Como somos seres relacionais, consideramos que ter boas relações são fundamentais para que o docente desempenho um bom trabalho, para o seu senso de pertencimento à instituição, afetando sua qualidade de vida, bem como a construção da sua autoimagem e autoestima. Sendo assim, perguntamos como era a relação com os estudantes, funcionários, com a direção escolar e com os demais professores. Assim, a tabela abaixo apresenta a percepção dos docentes diante das relações vivenciadas dentro da instituição escolar antes da pandemia.

Tabela 2.0 - Percepção da qualidade das relações dos docentes na escola

\begin{tabular}{|c|c|c|c|c|c|c|c|c|}
\hline & \multicolumn{2}{|c|}{$\begin{array}{c}\text { COM OS } \\
\text { ESTUDANTES }\end{array}$} & \multicolumn{2}{|c|}{ COM OS COLEGAS } & \multicolumn{2}{|c|}{$\begin{array}{c}\text { COM OS } \\
\text { FUNCIONÁRIOS }\end{array}$} & \multicolumn{2}{|c|}{$\begin{array}{l}\text { COM A DIREÇÃO } \\
\text { DA ESCOLA }\end{array}$} \\
\hline & $\mathbf{F}$ & $\mathbf{M}$ & $\mathbf{F}$ & $\mathbf{M}$ & $\mathbf{F}$ & $\mathbf{M}$ & $\mathbf{F}$ & $\mathbf{M}$ \\
\hline Excelente & & & & 1 & & 1 & 1 & 2 \\
\hline Muito boa & 4 & 3 & 4 & 2 & 6 & & 2 & 1 \\
\hline Mediana & & & & & & & 1 & \\
\hline
\end{tabular}


Ruim

Muito ruim

Fonte: Das autoras (2020).

Podemos inferir que estas boas relações com os colegas de trabalho tornam o clima relacional agradável e esse é um dos pontos positivos da escola, pelo menos do ponto de vista dos professores participantes da pesquisa. Enfim, estas respostas nos dão a entender que os educadores consideram que o ambiente de trabalho na escola é muito bom e que há boas relações entre os membros da instituição e estas são fundamentais não apenas para o bom desempenho das tarefas, como também na construção de um clima corporativo saudável. Assim, segundo Kenneth Gergen e Mary Gergen (2010, p. 13) "com nossas relações criamos e sustentamos as realidades em que vivemos". E são as relações que criam e sustentam o clima social escolar.

Apesar dessas respostas já indicarem um pouco da percepção dos professores sobre a instituição em que trabalham, consideramos que perguntar se eles matriculariam seus filhos naquela escola nos daria mais informações sobre como os docentes percebiam a qualidade do ensino na instituição. Uma professora e 3 professores assinalaram "sim", 2 professoras marcaram "talvez" e uma "não". Nenhum dos docentes afirmou "com certeza" ou "jamais", o que, de certa forma, corrobora a questão anterior sobre como viam a qualidade da escola. Estes dados da pesquisa apresentam o que Janosz, Georges e Parent (1998) denominam de “clima educacional”, que diz respeito à sensação de qualidade ou não do ensino na instituição.

Buscamos aprofundar a compreensão sobre se os professores estavam ou não satisfeitos com o ambiente de trabalho na instituição. Para Ederglenn Vieira Junior, Emerson Rasera e Carla Guanaes-Lorenzi (2017), compreender a educação como uma construção social refere-se a uma mudança em relação ao entendimento do conhecimento, abandonando a ideia de um aprendizado universal e válido para além de sua utilidade social e cultural. Tratase da transformação de uma orientação individualista na educação para uma orientação relacional. Em outras palavras, a proposta construcionista social para a educação diz respeito ao foco nos relacionamentos no processo de construção do mundo. 
Tabela 3.0 - Se o(a) docente pudesse, deixaria de trabalhar nesta escola?

\section{Sexo Feminino Masculino}

\begin{tabular}{lll}
\hline Com certeza & & \\
Sim & 1 & 1 \\
Talvez & 3 & 1 \\
Não & 1 \\
Jamais &
\end{tabular}

É bem curioso que nenhum deles tenha destacado que gostaria de mudar de instituição, embora 2 afirmassem que "talvez" mudariam. Notamos que, de maneira geral, os docentes responderam estar satisfeitos em trabalhar na escola, o que é muito positivo. Entretanto, não foi possível explorar que motivos os faziam considerar a instituição como um bom espaço de trabalho. Pelo fato de não quererem mudar de escola, acreditamos que essa pergunta nos aproxima do que Janosz, Georges e Parent (1998) denominaram "clima de pertencimento". Sentir-se pertencente a um determinado espaço significa, de acordo com os autores, transcender as outras facetas do clima social (relacional, educativo, de segurança e de justiça). $\mathrm{O}$ sentimento de pertencimento a uma escola se encontra nas relações estabelecidas com o ambiente físico, proteção, segurança, apoio e reconhecimento dos seus direitos, o que promove respeito pela instituição e pelas pessoas que interagem que, juntas, aderem às normas estabelecidas.

Há que considerar que, sendo uma cidade pequena e com uma única escola de ensino médio, não restavam aos professores muitos outros espaços de trabalho, nem de comparação. Ainda assim, as respostas foram bastante positivas e revelavam que, de maneira geral, havia um bom clima social escolar no ensino médio da escola, na percepção dos docentes.

Partindo do princípio de que as sensações de bem-estar e de acolhimento afetam diretamente o clima social escolar, perguntamos aos professores se eles consideravam que havia violência, racismo e bullying na escola. A percepção dos docentes é que há a presença desses três pontos na instituição escolar. No entanto, uma professora, inclusive, chegou a destacar que há bullying demais, enquanto os outros assinalaram: mais ou menos ou um pouco. Com relação à presença de violência ou racismo, 3 professoras e 2 professores assinalaram que havia e outros que consideraram que não (1 professora e 1 professor). Dos 


\section{OO DEVIR EDUCAÇÃO}

ISSN: 2526-849X

cinco professores que percebem racismo na escola, dois se declararam pardos, dois brancos e uma não declarou a cor, dessa forma, supomos que os educadores declarados brancos possuem sensibilidade para a questão do racismo, e talvez os docentes que se declararam pardos sofreram ou presenciaram alguma conduta discriminatória. Embora não tenhamos tido a possibilidade, nesta pesquisa, seria importante a escola explorar o que as pessoas consideram violência, bullying e que situações de racismo alguns professores presenciaram na escola e que passaram despercebidas a outros. Além disso, é importante enfatizar que esses são pontos muito sérios, na qual a escola deve ficar atenta, pois pode afetar o clima social da instituição. Portanto, a escola deve ter ações efetivas e claras de combate a toda forma de discriminação para que as pessoas se sintam confortáveis e seguras nela.

A perspectiva construcionista social nos ajuda a refletir sobre o respeito às diferenças existentes nos diversos mundos construídos dentro e fora de uma sala de aula. $\mathrm{O}$ construcionismo é uma prática reflexiva, construtiva, dialógica e relacional capaz de nos fazer compreender a importância das diferenças e enaltecê-las. E, consequentemente, visa a diminuição de práticas da violência contra a diferença do outro. Segundo Kenneth Gergen e Mary Gergen (2010, p. 12), o construcionismo "convida a novas formas de relação interpessoal, à ampliação das possibilidades de significação, à convergência entre domínios de significados divergentes, diminuindo os conflitos e promovendo a convivência humana". Portanto, mais uma vez, fortalecemos a defesa de que um bom clima social escolar depende de que a instituição esteja atenta à construção de bons vínculos entre todos os membros, repudiando toda forma de injustiça e preconceito, ainda que nas pequenas manifestações cotidianas que, ainda assim, podem ser bastante deletérias.

De acordo com Janosz, Georges e Parent (1998), o clima de segurança remete à confiança que as pessoas sentem quando estão inseridas no ambiente e isso gera condições para a concentração na realização das tarefas. Compreendemos que, quando esses fenômenos ganham destaque na escola, eles afetam o clima social e a qualidade de vida das pessoas que ali estão.

Segundo Kenneth Gergen (2009), a orientação construcionista social busca explicar os processos (que ocorrem de forma coletiva e não individualista) pelos quais as pessoas descrevem, explicam, ou, de alguma forma, dão conta do mundo em que vivem, incluindo-se a si mesmas. Então, para nós, explicar o processo de construção do clima social é 
compreender como são as relações das pessoas dentro do ambiente escolar porque são elas que constroem esse clima. De acordo com o autor,

Entendemos o mundo são artefatos sociais, produtos historicamente situados de intercâmbios entre as pessoas. Do ponto de vista construcionista, o processo de compreensão não é automaticamente conduzido pelas forças da natureza, mas é o resultado de um empreendimento ativo, cooperativo, de pessoas em relação. (GERGEN, 2009, p. 303).

Assim, as descrições e explicações sobre o clima social constituem, elas próprias, formas de ação social que estão entrelaçadas na cultura, na origem, nas questões socioeconômicas e políticas, entre outros, e, sobretudo, no resultado das relações humanas.

É importante destacar que 7 , dos 20 professores de ensino médio da escola, participaram da pesquisa. É possível que aqueles docentes com uma percepção menos positiva da escola não se sentissem à vontade para participar, ainda que houvesse uma garantia de sigilo na identificação dos participantes. Além disso, devemos salientar que o fato de a pesquisa ter sido feita durante o período de ensino remoto e de distanciamento social possa ter afetado os resultados, já que a intensidade das relações interpessoais cotidianas na escola não esteja acontecendo. Isso significou, certamente, numa mudança na relação com a instituição que afetou o clima social escolar. Professores, funcionários e estudantes continuavam vinculados à escola e tiveram que adaptar-se, de maneira bastante rápida e sem uma preparação antecipada, a todo um modelo novo de ensinar, e, portanto, considerando o momento em que a pesquisa estava sendo realizado, buscamos investigar como os docentes percebiam fatores relacionados ao clima social da escola, durante o período de distanciamento social.

\section{Percepções dos professores sobre fatores relacionados ao clima social da escola durante a pandemia}

O período de distanciamento social, embora tenha afetado a análise da construção do clima social escolar no cotidiano das relações interpessoais na instituição, nos permitiu investigar se os professores sentiam ou não falta das relações sociais com as pessoas que 
integram a escola, o que nos daria um indício significativo do clima social na instituição. Portanto, perguntamos aos educadores se eles estavam sentindo falta da escola e eles poderiam justificar a resposta. Através da questão: "Você está sentido falta da escola?" com as alternativas "muito", “em geral, sim", “às vezes", “em geral, não" e "não", todos os docentes responderam que estão sentindo falta da escola. Nesta questão, havia a oportunidade de justificar a resposta e quatro deles o fizeram, com as respostas que transcrevemos aqui da forma como foram redigidas: "o ambiente escolar é acolhedor, faz muita falta o contato direto com as pessoas"; "além da rotina de sair de casa para exercer uma atividade, os relacionamentos são agradáveis e fazem falta"; "sinto falta dos alunos e alunas"; "o clima na escola é muito agradável”. Estas respostas indicam muito claramente que os professores participantes sentiam falta da convivência cotidiana na escola, o que é um indicador bastante evidente de que, para eles, a escola tinha um bom clima social, do qual gostavam de participar.

Em virtude do contexto pandêmico, as relações sociais passaram a ser construídas por meio dos ambientes virtuais e não mais presenciais e isso implicou em uma outra forma de se relacionar. Assim, as relações virtuais também implicam na construção do clima escolar, visto que professores e alunos estavam distantes geograficamente, mas continuavam a se relacionar.

\section{Considerações finais}

O clima social escolar consiste numa sensação generalizada que não precisa ser a mesma para todas as pessoas e nem em todos os momentos. Uma escola que apresenta um bom clima social não é perfeita, sem conflitos ou dificuldades, mas aquela em que, de maneira geral, as pessoas se sentem bem e se consideram acolhidas naquele lugar, ainda que existam momentos em que isso não aconteça. O desejável, em relação ao clima social de uma escola, é que absolutamente todos tenham direito a um ambiente saudável e educativo, em que todos importam e são considerados neste processo.

Nesse sentido, compreendemos que não há um modelo ideal para construirmos um clima social de "referência" numa escola. Cada clima possui suas peculiaridades, pois cada instituição escolar está situada em uma determinada comunidade que possui relações 
culturais, econômicas, políticas, sociais, afetivas e históricas diferentes de outras comunidades.

No caso dessa pesquisa, os professores afirmaram ter boas relações sociais dentro da escola, o que contribui para a percepção de um bom clima na instituição. Diante da necessidade de distanciamento social, professores e estudantes deixaram de conviver diariamente nos espaços da escola, mas mantiveram suas relações num contexto virtual e à distância. Foi desafiador investigar o clima social escolar não havendo contato interpessoal tão intenso quanto antes, mas consideramos que, ainda assim, alunos, professores e funcionários permaneciam membros daquela instituição e com alguma forma de relação interpessoal. As relações sociais são fundamentais para a construção do clima social escolar de maneira presencial ou virtual, cada uma com suas especificidades. Dessa forma, mesmo no contexto pandêmico, as relações acontecem e são capazes de construir espaços, significados, sentimentos, como também o clima social. Além disso, era uma chance de perguntar se os professores sentiam ou não falta das relações interpessoais na escola, o que seria um excelente indicador da existência ou não de um bom clima social na escola.

Pelas respostas obtidas, pareceu-nos, que nesse contexto de pandemia, os docentes passaram a valorizar e compreender a importância das relações, sobretudo na escola. Os educadores fizeram questão de justificar sua resposta sobre a falta que sentiam da escola, destacando a ausência do contato interpessoal com os colegas e os estudantes. Percebemos que os professores identificavam de maneira muito positiva o clima social da escola. Estes resultados foram devolvidos à escola com o objetivo de auxiliar na manutenção deste bom ambiente e de se enfatizar a importância de que todos se sintam bem na instituição, com a inclusão daqueles que, de alguma forma, não se percebem tão bem acolhidos.

Criar e manter boas relações interpessoais é importante não apenas no ensino presencial. O ensino remoto não exclui as relações, apenas as distancia, e neste sentido, pode ser ainda mais importante desenvolver o senso de pertencimento e bem-estar. O contexto do distanciamento não exime a escola de cuidar do seu clima social, podendo ser, ao contrário, um momento muito significativo para a instituição busque que todos os professores se sintam envolvidos e comprometidos com as atividades institucionais. Um bom clima social de uma instituição escolar é fator fundamental para se alcançar bons resultados da aprendizagem, mas também para cuidar da qualidade de vida das pessoas, num momento de tanta insegurança e temor causados pela pandemia e pela crise econômica brasileira. Defendemos, portanto, que 
as escolas estejam atentas ao clima social, visando preservar um sentimento de pertença entre todos os atores escolares, reconhecendo e valorizando a cada um. Neste momento, o distanciamento é fundamental para preservar vidas, mas o acolhimento e a proximidade podem e devem ser dar de outras formas, pois, mesmo distantes, as pessoas estão lá e as relações continuam a ser importantes, talvez agora até mais do que antes.

\section{Referências}

ARANTES, Valéria Amorim. Afetividade, cognição e moralidade na perspectiva dos modelos organizadores do pensamento. In: ARANTES, Valéria Amorim. Afetividade na escola: alternativas teóricas e práticas. São Paulo: Summus, 2003.

ARON, Ana María; MILICIC, Neva; ARMIJO, Iván. Clima Social Escolar: una escala de evaluación - Escala de Clima Social Escolar, ECLIS. Univ. Psychol., Bogotá, v. 11, n. 3, 2012. Disponível em: https://revistas.javeriana.edu.co/index.php/revPsycho/article/view/749. Acesso em: 23 fev. 2021.

BEAUDOIN, Marie-Nathalie; TAYLOR, Maureen. Bullying e desrespeito: como acabar com essa cultura na escola. Porto Alegre: Artmed, 2006.

CADONÁ, Eliane; SCARPARO, Helena. Construcionismo social na atenção básica: uma revisão integrativa. Ciência \& Saúde Coletiva, v. 20, n. 9, p. 2721-2730, 2015. Disponível em: https://www.scielo.br/pdf/csc/v20n9/1413-8123-csc-20-09-2721.pdf. Acesso em: 23 fev. 2021.

CARDOSO, David Tiago. Construcionismo social: em direção à assistência social. Nova Perspectiva Sistêmica, v. 26, n. 58, 2017, p. 60-73. Disponível em: http://pepsic.bvsalud.org/pdf/nps/v26n58/n26a05.pdf. Acesso em: 23 fev. 2021.

CARDOSO, David Tiago; BEIRAS, Adriano. Contribuições do construcionismo social para o estudo das masculinidades. In: Seminário Internacional Fazendo Gênero 11 \& 13th Women's Worlds Congress, 2017, Florianópolis. Anais [...]. Florianópolis, 2017. Disponível em: http://www.en.wwc2017.eventos.dype.com.br/resources/anais/1503076997_ARQUIVO_Cont ribuicoesdoCSparaoestudodasmasculinidades[textocompleto].pdf. Acesso em: 23 fev. 2021.

CEIA, Alda Maria dos Reis. Um olhar de dentro: o clima de escola na perspectiva dos alunos. 2011. 164 f. Dissertação (Mestrado em Administração e Gestão Educacional) Departamento de Educação e Ensino a Distância, Universidade Aberta de Portugal, 2011. Disponível em: https://repositorioaberto.uab.pt/bitstream/10400.2/2055/1/Alda\%20Ceia.pdf. Acesso em: 23 fev. 2021.

CORNEJO, Rodrigo; REDONDO, Jesús M. El clima escolar percibido por los alumnos de enseñanza media. Una investigación en algunos liceos de la Región Metropolitana. Ultima 
Década, Cidpa Viña Del Mar, v. 9, n. 15, p. 11-52, 2001. Disponível em: https://scielo.conicyt.cl/pdf/udecada/v9n15/art02.pdf. Acesso em: 23 fev. 2021.

GERGEN, Kenneth J.; GERGEN, Mary. Construcionismo social: um convite ao diálogo. Rio de Janeiro: Instituto Noos, 2010.

GERGEN, Kenneth J. O movimento do construcionismo social na Psicologia Moderna. Revista Internacional Interdisciplinar INTERthesis, Florianópolis, v. 6, n. 1, p. 299-325, 2009. Disponível em: https://periodicos.ufsc.br/index.php/interthesis/article/view/18071384.2009v6n1p299/10807. Acesso em: 23 fev. 2021.

GUERRA VIO, Cristóbal et al. Percepción del Clima Escolar en Estudiantes de Enseñanza Media de Valparaíso de Colegios Municipales, Particulares Subvencionados y Particulares. Estudios Pedagógicos, Valdivia, v. 38, n.2, p. 103-115, 2012. Disponível em: https://scielo.conicyt.cl/pdf/estped/v38n2/art07.pdf. Acesso em: 23 fev. 2021.

JANOSZ, Michel; GEORGES, Patricia; PARENT, Sophie. L'environnement socioéducatif à l'école secondaire: un modèle théorique pour guider l'évaluation du milieu. Revue Canadienne de Psycho-Éducation, v. 27, n. 2, p. 285-306, 1998. Disponível em: https://www.researchgate.net/publication/255635944_L'environnement_socioeducatif_a_l'eco le_secondaire_Un_modele_theorique_pour_guider_l'evaluation_du_milieu. Acesso em: 23 fev. 2021.

PÉREZ, Cruz Pérez. Educacion para la convivencia como contenido curricular: propuestas de intervencionenel aula. Estudos Pedagógicos, n. 25, p. 113-130, 1999. Disponível em: https://scielo.conicyt.cl/scielo.php?script=sci_arttext\&pid=S0718-07051999000100007.

Acesso em: 24 fev. 2021.

OESSELMANN, Dirk. Clima escolar. Belém: Unama, 2009.

PORTAL EDUCAÇÃO, 2013. Disponível em: https://siteantigo.portaleducacao.com.br/conteudo/artigos/direito/plano-de-unidade-deensino/30231 . Acesso em: 30 nov. 2020.

RASERA, Emerson Fernando; JAPUR, Marisa. Os sentidos da construção social: o convite construcionista para a Psicologia. Paidéia, v. 15, n. 30, p. 21-29, 2005. Disponível em: https://www.scielo.br/pdf/paideia/v15n30/05.pdf. Acesso em: 24 fev. 2021.

SAMPSON, Edward E. Celebration the other: the dialogic turn. In: GERGEN, Kenneth J.; GERGEN, Mary. Celebration the other: a dialogic account of human nature. Ohio: Taos Institute Publication, 2008.

SOUZA, Rita de Cássia de. Uma análise construcionista social da liberdade na educação. Periódico Horizontes, v. 38, n. 1, p. p. e020034, jul. 2020. Disponível em: https://revistahorizontes.usf.edu.br/horizontes/article/view/760/449. Acesso em: 24 fev. 2021.

Recebido em: 25/06/21

Revista Devir Educação, Lavras-MG. Edição Especial, p.71-89, Set./2021. 
Publicado em: 20/07/21

Revista Devir Educação, Lavras-MG. Edição Especial, p.71-89, Set./2021. 